\title{
Rádios Livres e Rádios Comunitárias no Brasil
}

\section{Mauro Sá Rego Costa ${ }^{1}$}

\section{Resumo:}

A história das rádios livres no Brasil reflete e dá continuidade à luta pelas rádios livres na Itália e na França nos anos 70 e 80. A luta pela democratização do rádio levou à criação da Radiodifusão Comunitária, pela Lei 9.612, de 1998 - difusão em freqüência modulada (FM), de baixa potência ( 25 Watts) e cobertura restrita a um raio de $1 \mathrm{~km}$ a partir da antena transmissora. É das legislações mais restritivas no mundo tanto em abrangência no raio quanto nas condições de organização das emissoras - veto a recursos de publicidade e à formação de redes -. Mesmo assim, a busca de concessões de licenças de emissão ainda é manipulada por interesses macropolíticos. E diante das 3.400 licenças já concedidas, há 30.000 rádios no ar - rádios livres ilegais, portanto, mas na sua maioria não respondendo igualmente a interesses comunitários controladas por grupos religiosos, o pequeno comércio e a política local. A rádio digital e outras novas mídia populares e livres na internet tendem a tornar inócuos estes dilemas e limites.

\begin{abstract}
:
The history of free radio in Brazil follows the Italian and French influence from the 70's and 80's. The movement for the democratization of radio led to the creation of a Community Radio law - the 9.612, in 1998 - for the transmission in FM, with a 25w power, and restriction of a 1 $\mathrm{km}$ circle. It's one of the more restrictive legislations in the world, barring the use of advertising and networking. . Even so, the demand for radio broadcast licenses is still manipulated by macropolitical interests. Considering the 3.400 licenses already granted, there are 30.000 radios on air - free, therefore illegal radios, but most of them do not respond to community interests - controlled by religious groups, the small business and local politics. Digital radio and other new popular and free media on the internet tend to cancel these dilemmas and limits.
\end{abstract}

Para entender a história e a atual situação das rádios comunitárias no Brasil, consideramos necessário um preâmbulo conceitual. Trata-se de uma história com muitas camadas heterogêneas e contraditórias entre si, em que se misturam o desejo autêntico dos movimentos sociais pela democratização das comunicações; a resistência do sistema instituído da mídia, altamente oligopolizado e com representação política poderosa em todos os níveis de governo; uma legislação limitadora do alcance (abrangência do sinal) e da sustentabilidade das emissoras comunitárias; a infiltração daquele mesmo poder

\footnotetext{
${ }^{1}$ Professor do PPG em Educação, Cultura e Comunicação da FEBF/UERJ; Coordenador do Laboratório de Rádio e do Estúdio de Som e Música da FEBF.
} 
político instituído na tentativa de controle desse novo sistema de comunicação; uma saída para o sistema (agora ilegal) das rádios livres, utilizado tanto pelos movimentos sociais quanto por interesses comerciais (de pequena monta), por grupos políticos locais (prefeituras, vereadores), e por uma crescente e ampla rede de igrejas evangélicas populares; a perseguição policial e judicial dessas emissoras ilegais, cujo número já ultrapassa largamente as possibilidades materiais da eficácia da ação repressiva; as mudanças nas tecnologias de informação e comunicação que ampliam o alcance ou até substituem projetos de radio comunitária (webradios, blogs, sites); o apoio crescente de outra área de governo - do Ministério da Cultura - com seu projeto de distribuição de meios de desenvolvimento cultural para as camadas populares (os Pontos e os Pontões de Cultura) e cujos grupos criam suas rádios comunitárias, e/ou estimulam (em cursos e oficinas) a criação de rádios locais (legais ou “ilegais”). Os projetos do Ministério da Cultura devem muito à atuação durante sete anos do Ministro Gilberto Gil, compositor e cantor pop politicamente progressista, com o apoio do presidente Lula. É bom lembrar que Gilberto Gil faz parte do movimento Creative Commons (do qual participava mesmo enquanto Ministro) e liberou os direitos autorais de grande parte de sua produção musical.

Para entender o desenho político deste processo é preciso recorrer à compreensão das correlações entre a macropolítica (partidos, governos....) e as micropolíticas (de muitos tipos e escalas) que atravessam os movimentos sociais e se misturam, como resistência (ou, ao contrário, como pequenos elos capitalísticos) muitas vezes em aliança com instancias macropolíticas mais progressistas. É impossível calcular os efeitos e resultados políticos a médio e longo prazo deste verdadeiro rizoma. Citando o filósofo Michel Serres,

[...] qualquer acontecimento da história é multitemporal, remete ao revolvido, ao contemporâneo e ao futuro simultaneamente. Tal ou qual objeto, esta ou aquela circunstância, são pois policrônicas, multitemporais, fazem ver um tempo amarrotado, multiplamente dobrado ${ }^{2}$.

As iniciativas micropoliticas se estendem de modo difícil de perceber, movimentos subterrâneos, longe do olhar da mídia dominante, aparentemente

\footnotetext{
${ }^{2}$ Citado por Peter Pál Pelbart em "Bárbaros e Ameríndios em Mundobráz!" in http://www.sibila.com.br/index.php/critica/1698-barbaros-e-amerindios-em-mundobraz- (acesso em 20/02/2011)
} 
fragmentados, descoordenados e sem importância, só se tornam visíveis de forma súbita e imprevisível em momentos determinados. ${ }^{3}$

\section{No começo...}

As primeiras rádios livres no Brasil parecem anedotas zen. A primeira, montada por dois irmãos adolescentes, no Espírito Santo, em 1970, em plena ditadura militar, resultou na prisão de um deles e de seu pai pela Policia Federal. Tiveram que provar - o que na época exigia bons relacionamentos e bons advogados - que não tinham relações com o movimento comunista. Em seguida, conta a lenda, um professor de escola técnica em Sorocaba, São Paulo, ensina a seus alunos a construir transmissores de rádio. Resultado: quase 50 rádios estavam no ar na cidade entre 1982 e 1983. Daí surgiu a primeira organização de rádios livres brasileiras, o Conselho das Rádios Clandestinas de Sorocaba (CRCS), que tentou - em vão - organizar as emissoras para que não transmitissem umas sobre as outras ou interferissem nas FMs comerciais. O fechamento de algumas emissoras e a ameaça policial de fechamento de todas foi suficiente para calar as vozes livres de Sorocaba. ${ }^{4}$

Mas em 1985, ano da redemocratização do país, São Paulo enche-se de rádios livres - Xilic, Ítaca, Molotov, Totó, Ilapso, Trip, Tereza, Se Liga Suplicy... - . Xilic, na sua primeira transmissão, cita a Radio Alice de Bolonha e o Plastic People of the Universe, o rock resistente anti-soviético de Praga ${ }^{5}$. São todas rádios libertárias, mais pra Maiakóvski que Lenine; mao-dadaístas, como Alice; tropicalistas, produzidas por jovens e universitários. O movimento se espalhou por todo o país, dispersamente, mas intenso.

O movimento no Brasil inspirou-se nos movimentos na Itália (anos 70) e na França (anos 80), como projeto de ampliar a comunicação democrática e sair do controle principalmente comercial, com que esta mídia estava organizada no país. Não mostra nenhuma continuidade com o rádio como meio de luta sindical (Bolívia, anos

\footnotetext{
${ }^{3}$ Macropolítica, micropolitíca e rizoma são conceitos da teoria política de Gilles Deleuze e Felix Guattari. em Mil Platôs. Capitalismo e Esquizofrenia , publicado no Brasil entre 1995 e 1997, em 5 volumes, pela Editora 34, Rio de Janeiro.

${ }^{4}$ Claudia de Abreu. Tribuna da Imprensa, Segundo Caderno, Nov./25/1995, p.1.

${ }^{5}$ MACHADO, Arlindo; MAGRI, Caio; MASAGÃO, Marcelo. Rádios Livres a reforma agrária no ar. São Paulo, Brasiliense, 1986, 53-56 e 153.
} 
50-60) ou revolucionária (Cuba, Guatemala, El Salvador), exemplos recentes na América Latina.

Na primeira tentativa de juntar emissoras de vários estados, em 1986, no Rio de Janeiro formaram-se duas entidades: a ABOLA, Associação Brasileira das Ondas Livres do Ar e a CORA-LIBRA, Cooperativa de Rádios Livres do Brasil ${ }^{6}$. Claudia de Abreu relata que, nos anos seguintes, houve uma diminuição no número de emissoras, até que o movimento é retomado, em 1989, com o I Encontro Nacional sobre Rádios Livres, em São Paulo. Organizado pela UNE - União Nacional dos Estudantes -, o encontro contou com representantes de dez estados e aprovou a criação de um coletivo nacional, que buscaria o apoio da sociedade civil pela democratização da comunicação. Em 1990, começaram a surgir os pré-Comitês pela Democratização dos Meios de Comunicação. Em 1991, foi lançada a Frente Parlamentar pela Democratização da Comunicação, em Brasília, com a presença do Coletivo Nacional de Rádios Livres. Foi somente em 1993, no entanto, que o movimento de rádios livres entrou oficialmente para a coordenação do Fórum Nacional pela Democratização da Comunicação.

\section{A legislação das comunitárias}

Com muitos avanços e recuos o movimento consegue finalmente, através da Comissão de Comunicação, Tecnologia e Informática, em fevereiro de 1998, levar ao plenário do Congresso e aprovar a lei que regulamenta a radiodifusão comunitária. Da proposta de projeto de lei do movimento organizado só se conseguiu aprovar $10 \%$ dos itens definidos. No período da tramitação da lei, 70\% dos membros da Comissão no Congresso eram donos ou tinham interesses indiretos em empresas de rádio e televisão ${ }^{7}$. Daí não poderia se esperar grande coisa. Mas o “movimento” preferiu aceitar a lei como um primeiro passo para se continuar lutando por uma regulamentação mais justa e democrática... Infelizmente, o segundo passo ainda não foi dado.

A lei (Lei 9.612/1998) limita o alcance das emissoras a um quilômetro de raio e a potência dos transmissores a um máximo de 25 watts; dispõe deuma única freqüência no dial para as milhares de emissoras a serem criadas; isto só é modificado quando a Anatel (Agência Nacional de Telecomunicações, autarquia federal que regula e

\footnotetext{
${ }^{6}$ Claudia de Abreu, 1995.

${ }^{7}$ COSTA, M. J. S. R. ; HERMANN, Wallace . Rádios livres, rádios comunitárias: outras formas de fazer rádio e política. Lugar Comum (UFRJ), Rio de Janeiro, v. 16-17, p. 97-107, 2002.
} 
fiscaliza os serviços de telecomunicações do Brasil) descobre algum impedimento local; proíbe a captação de recursos de publicidade para a sustentação da emissora; proíbe a formação de rede entre as emissoras, salvo em caso de calamidade pública; e não garante às emissoras comunitárias proteção contra a interferências de emissoras comerciais e serviços de telecomunicação.

Estes limites são largamente criticados como impeditivos de uma verdadeira opção democratizante de comunicação popular. Em primeiro lugar, por dificultar a sustentação econômica para as rádios funcionarem. Com a proibição da publicidade, fica impossível profissionalizar seus agentes e até pagar custos básicos como aluguel de um espaço, contas de luz e telefone. Para completar, uma Norma Complementar 2/98 estabelece que “a separação mínima entre duas estações de RadCom será de 3,5km”. A lei, na prática, só permite a existência de uma rádio comunitária em cada município.

Com todos estes limites, a procura pela licença para transmissão comunitária é enorme. E há um apoio contínuo de grandes ONG's para a criação de novas emissoras, assim como apoio mútuo, dentro do movimento, para a capacitação de pessoal para as emissoras. Alguns exemplos recentes: a ONG Jequitibá organiza "Curso de Radiojornalismo para Comunicadores Populares” em Santarém, no Pará, e em Brasília (21/6 e 28/6/2010); em 2008 e em 2009, a Jequitibá promoveu o mesmo curso no Rio de Janeiro, em Recife, Aracaju e Salvador, com apoio da UNESCO, da prefeitura de Genebra, da Embaixada da Suíça no Brasil, dos governos estaduais da Bahia e Pernambuco, das Universidades Federais de Sergipe e Brasília, da Associação Brasileira das Rádios Comunitárias (Abraço) e da ONG Viva Rio, do Rio de Janeiro ${ }^{8}$; a própria Abraço promove constantemente cursos como o "de Comunicação Popular e Tecnologias Livres”, durante seu congresso em Curitiba ${ }^{9}$.

Outros parceiros importantes são os Pontos de Cultura, programa do Ministério da Cultura sobre o qual falarei mais adiante. Assim o Ponto de Cultura Cantiga de Ninar (Itabaiana/Paraíba) organizou, por três meses, a partir de setembro/2010 oficinas de rádio comunitária e rádio web, em parceria com a Rádio Comunitária Voz Popular, do

\footnotetext{
${ }^{8}$ http://www.unesco.org/pt/brasilia/singleview/news/unesco and the ngo jequitiba promote a radio journalism training course for commu nicators from community radio stations/back/9679/cHash/1a4ba4b513/ (in nov./6/2010)

| ${ }^{9}$ http://agenciaabraco.org/noticia/72 (in nov./6/2010)
} 
bairro de São Rafael em João Pessoa ${ }^{10}$. O Ponto de Cultura Adilson Duarte de Ipiaú, Bahia, oferece Oficina de Radialismo Comunitário, com o apoio da Rádio Livre Comunitária de Ipiaú (fev. 2010) ${ }^{11}$; o Ponto de Cultura Zabelê, junto com a Rádio Comunitária Zabelê, oferecem formação em rádio, em Remanso, município do Sertão do Rio São Francisco ${ }^{12}$; Rádio Comunitária Campeche, junto com Focu - Pontão Fomento Cultural no pólo Florianópolis - oferecem oficinas de animação, documentário e som para os pontos de cultura e rádios comunitárias ${ }^{13}$.

E ainda, com todos os limites, o interesse pela regulamentação de rádios comunitárias pelo Ministério das Comunicações tornou-se outro canal de clientelismo político e naturalmente um fator de influencia nas eleições locais. A estimativa é de que cerca de 50\% das 3.497 rádios comunitárias que hoje funcionam legalmente no País, tenham contado com as bênçãos de padrinhos políticos. Senadores e deputados, ligados a entidades que sempre têm um político municipalista por trás - um prefeito ou um vereador - pressionam para acelerar a tramitação do processo de autorização das rádios e assim passam, ambos, a ter canal cativo nos períodos eleitorais ${ }^{14}$. O uso eleitoral das emissoras de rádio FM e AM por políticos não é novidade, a nível estadual e federal.

Foram divulgados em março passado novos resultados de levantamento feito pelo Instituto de Estudos e Pesquisas em Comunicação (EPCOM) que revelam que 271 políticos brasileiros, no exercício de mandato eletivo, possuem vínculo direto e oficial com veículos de radiodifusão, isto é, são sócios ou diretores de 348 emissoras de radio e/ou televisão. Desses, 147 são prefeitos (54,24\%), 48 (17,71\%) são deputados federais; 20 (7,38\%) são senadores; 55 (20,3\%) são deputados estaduais e um é governador ${ }^{15}$.

Aí não estão contabilizadas as relações informais e indiretas (por meio de parentes e "laranjas") que envolvem muitos dos demais parlamentares a emissoras de rádio e TV. A extensão desta prática à manipulação das comunitárias, assim, não passa de repetição de velho modelo. Franklin Martins, ministro da Secretaria de Comunicação

\footnotetext{
${ }^{10}$ http://pccn.wordpress.com/2010/08/29/ponto-de-cultura-vai-oferecer-oficinas-de-radio-comunitariae-radio-web-em-setembro/ (in nov./6/2010)

${ }^{11}$ http://pontodeculturaipiau.blogspot.com/2010/02/oficina-de-radialismo-comunitario-e.html (in nov./6/2010)

${ }^{12}$ http://pontoapontobahia.wordpress.com/remanso-radio-comunitaria-zabele-fm/ (in nov./6/2010)

${ }^{13} \mathrm{http}$ ://blog.radiocampeche.com.br/2010/05/radio-comunitaria-campeche-98-3-informa/ (in nov./6/2010)

${ }^{14}$ http://www.jornaldelondrina.com.br/online/conteudo.phtml?t|=1\&id=982919\&tit=Politicosaceleram-concessao-de-radios-comunitarias - (in nov./6/2010)

${ }^{15}$ Ver http://www.jurisciencia.com/artigos/coronelismo-eletronico-de-novo-tipo/70/ (in nov./6/2010).
} 
Social, chegou a propor que a regulamentação das telecomunicações e da radiodifusão fosse prioridade do próximo governo - e a proibição de quem ocupa cargo eletivo ser concessionário de meio de comunicação de massa, que já consta da lei, deva ter regulamentação mais estrita ${ }^{16}$.

Os entraves para a regulamentação das comunitárias junto ao Ministério das Comunicações produz, no entanto, um efeito mais amplo: além das 3.947 rádios já legalizadas $^{17}$, há cerca de 30.000 rádios de pequena potencia no ar no país, pelas contas da Abraço. Como encarar este fato? No inicio do governo Lula, em 2003-2004, foi criada uma comissão ad-hoc no Ministério para fazer um diagnóstico da situação e propor novos meios para melhor selecionar e agilizar as concessões a novas rádios. Nesse momento, já havia umas 15.000 rádios no ar sem concessão.

Depois de um ano, no entanto, essa comissão não conseguiu avançar muito, A maior dificuldade era como classificar as rádios "ilegais" para permitir seu acesso a concessões. Quase metade das rádios ilegais pertenciam a igrejas evangélicas, outra grande parcela eram rádios "particulares" montadas por pequenos comerciantes vendendo ilegalmente publicidade, além das rádios de políticos locais, vereadores, na maioria. Um número reduzido correspondia a rádios comunitárias stricto sensu, ligadas a associações de moradores e outros grupos locais.

O problema é que mesmo entre as rádios ligadas a igrejas e rádios “particulares”, havia um número de emissoras que funcionavam nos moldes das comunitárias, tratando de problemas vividos pela população local, e dando voz a grupos organizados e artistas locais. Por que não poderiam ser incorporadas, a partir de pequenas mudanças na sua organização e no seu funcionamento, e ganhar também o status de comunitárias? A comissão não conseguiu encontrar caminhos regulamentares para discriminar as rádios existentes e modificar as regras para concessões.

Outra reação foi tentada com uma série de lutas por legislação municipal que fizesse a outorga de concessões a partir das prefeituras. Várias leis foram aprovadas,

\footnotetext{
${ }^{16}$ Lúcio Lambranho . Parlamentares donos de rádio e TV sob pressão. In: http://www.observatoriodaimprensa.com.br/artigos.asp?cod=446IPB006 (in nov./16/2010)

${ }^{17}$ Número encontrado na página do Ministério das Comunicações em 13 de junho de 2011 http://www.mc.gov.br/images/radio-comunitaria/licenciamento/Rel radcom licenca definitivabrasil 2011-06-13.pdf
} 
como a da cidade de São Gonçalo, no estado do Rio de Janeiro ${ }^{18}$ e de Campinas, no estado de São Paulo ${ }^{19}$; assim como Pontalina, em Goiás (lei municipal 001/2004 e regulamentação 064/2004 de 2004). A Assembléia Legislativa do estado do Piauí aprovou legislação estadual para a outorga de concessões. ${ }^{20}$ Toda esta legislação entra em choque com a legislação federal, que pela Constituição é a única instancia responsável pelo controle das telecomunicações no país. A tentativa é criar conflitos judiciais que tenham que ser decididos nos tribunais estaduais. Até o município de São Paulo teve sua lei aprovada em 2005 (a Lei 14.013 sancionada pelo prefeito José Serra) $)^{21}$.

Isso não impediu que, em 8 de abril de 2009,

“(...) a Anatel protagoniz(asse) um curioso ato público com palco montado no hangar da Vasp - Viação Aérea de São Paulo, no aeroporto de Congonhas (...).Tendo como platéia o prefeito de São Paulo, Gilberto Kassab, a vice-prefeita, secretários municipais, funcionários da Anatel, além de policiais federais e jornalistas convidados, entrou em cena um trator com rolo compressor e destruiu cerca de oito toneladas de equipamentos apreendidos em operações de fiscalização de emissoras de rádio comunitárias e piratas. Ao todo, 17 mil discos e cds,750 transmissores, 70 antenas e dezenas de computadores e aparelhos de som viraram sucata. (...) Eles teriam sido apreendidos nos últimos cinco anos, em todo o estado, e correspondiam a dois mil processos concluídos pela Justiça, que autorizara sua destruição”22.

Para o prefeito Kassab, o material foi destruído para mostrar que não haverá tolerância: "Nosso objetivo é fechar todas as rádios piratas e ilegais. Se é clandestina, tem que ser eliminada”, sentenciou. Dirigentes de entidades e de organizações sociais ligadas a movimentos de defesa da democratização dos meios de comunicação compararam o episódio às conhecidas práticas ditatoriais típicas de estados totalitários. $^{23}$

\section{Um caos criador}

Bom, a impressão que se tem do quadro mais amplo, assim, é de algo caótico. E isto é o que se pode considerar como mais preciso, mais perto da realidade. A

\footnotetext{
${ }^{18} \mathrm{http}: / /$ www.radiolivre.org/node/884 (in nov./13/2010)

${ }_{19}^{19}$ http://www.piratininga.org.br/artigos/2005/64/nogueira-campinas.html (in nov./13/2010)

${ }^{20} \mathrm{http://www.portalotamboril.com.br/noticias/-953.html} \mathrm{(in} \mathrm{nov./13/2010)}$

${ }^{21}$ http://www.radiolivre.org/node/997

${ }^{22}$ Ana Luisa Zaniboni Gomes. "Gritos parados no ar: uma reflexão sobre processos de interdição em rádios comunitárias". In X Encontro dos Grupos de Pesquisa em Comunicação - GP Rádio e Mídia Sonora, INTERCOM, Caxias do Sul, set. 2010.

${ }^{23}$ Idem, Ana Luisa Zaniboni Gomes.
} 
informação sobre e o interesse pela criação de rádios locais se dissemina por n caminhos. Atualmente, em função das restrições legais, e das mudanças na base tecnológica das comunicações, estas informações são acompanhadas pelas dos meios disponíveis na internet - tanto em relação à web rádio quanto a montagens de sites e blogs associados às rádios locais, ou no lugar delas como canal para divulgação, comunicação e realização de ações culturais, artísticas e/ou políticas locais.

Assim se disseminam tanto pequenas rádios “ilegais” que surgem e desaparecem com freqüência, com ou sem a repressão policial instituída, quanto acontecem intervenções de coletivos locais utilizando os meios internautas, associados, às vezes, à implantação provisória de uma emissora de radio.

Um exemplo recente: durante a realização do Fórum Social Urbano, evento paralelo ao Fórum Mundial Urbano (Rio de Janeiro, 22 a 26 de março 2010), um grupo formado por várias entidades resolveu instalar uma rádio que transmitiria localmente e via internet uma cobertura do Fórum. Faziam parte do grupo a Rádio Kaxinawá, ${ }^{24}$ o Pontão da $\mathrm{ECO}^{25}$, e um coletivo de artistas chamado Jogos de Escuta ${ }^{26}$. A rádio foi instalada - Radio Portoarea - transmitindo diariamente para uma área do centro da cidade do Rio uma programação com entrevistas e o áudio das mesas redondas e outras atividades acontecendo no Forum. Um problema técnico impediu a transmissão simultânea em web radio, mas o Jogos de Escuta montou um blog para transmitir parte da produção da rádio - http://radioportoarea.espectroaberto.org/. A rádio só durou quatro dias - de 22 a 25 de março - mas o blog com a cobertura em áudio do evento ainda pode ser acessado.

\section{O apoio do Ministério da Cultura}

Muitos projetos culturais locais, com mais tempo de permanência, incluindo modos tradicionais de música, dança e poesia, vem recebendo apoio do governo federal através do Programa dos Pontos de Cultura, do Ministério da Cultura. Este é, certamente, o programa mais amplo de apoio ao desenvolvimento cultural já

\footnotetext{
${ }^{24}$ Rádio Comunitária que inclui o Laboratório de Radio da FEBF/ UERJ - Universidade do Estado do Rio de Janeiro - junto com outros grupos da comunidade de Vila São Luís, um bairro de Duque de Caxias, na periferia do Rio de Janeiro.

${ }^{25}$ Grupo universitário que dá suporte técnico/pedagógico aos Pontos de Cultura apoiados pelo Ministério da Cultura; ECO é a Escola de Comunicação / Universidade Federal do Rio de Janeiro.

${ }^{26}$ Coletivo de artistas que trabalha com interfaces sonoras, inclusive o rádio.
} 
desenvolvido no país, com o foco na enorme diversidade que caracteriza a vida cultural brasileira.

É a cultura financiada de baixo para cima, permitindo a afirmação dos grupos culturais nas suas diferenças - museus dentro de favelas, preservação da memória em grupos quilombola ${ }^{27}$, ou a formação de grupos de produção de vídeo em aldeias indígenas, apoio a grupos que mantêm formas tradicionais de dança e música como o Jongo da Serrinha ${ }^{28}$, ou os Maracatus ${ }^{29}$ em Pernambuco, e, ao mesmo tempo, a grupos de periferias urbanas que desenvolvem a cultura digital - arte de computador, ensino da criação de blogs e sites na internet, ou rádios comunitárias (sempre associadas às tecnologias digitais).

Cada Ponto de Cultura aprovado recebe $\mathrm{R} \$ 180.000,00$ para o desenvolvimento de sua infraestrura e atividades durante três anos. E segundo o Ministério da Cultura já existem quatro mil Pontos de Cultura em 1122 municípios do Brasil, o que implica no atendimento de oito milhões e 400 mil pessoas em todo o país. ${ }^{30}$

Então, o mesmo Ministério das Comunicações que, seguindo a legislação restritiva, é um obstáculo ao desenvolvimento de maior número de rádios comunitárias, estabelece parcerias com os Ministérios da Cultura, da Ciência e Tecnologia, da Agricultura para criar 11.356 pontos de conexão gratuita à internet em todo o país. Estes pontos incluem escolas públicas, bibliotecas, pontos de cultura, aldeias indígenas, comunidades quilombola, assentamentos rurais, etc. ${ }^{31}$ Um novo edital do Ministério das Comunicações propõe ampliar para 100 mil o número de pontos em todo o país. Muitos destes pontos já estão associados a rádios comunitárias (legais ou “ilegais”) para sua transmissão em webradio.

Outro projeto do Ministério da Cultura criou os Pontões de Cultura, para articular os Pontos de Cultura, estabelecer a integração e o funcionamento da rede dos Pontos de Cultura (principalmente via internet). Os Pontões aprovados recebem

\footnotetext{
${ }^{27}$ Quilombolas são residentes remanescentes de Quilombos: terra ocupada por escravos fugitivos, antes da Abolição da Escravatura (1888). Muitas dessas comunidades ainda existem.

28 Jongo é uma forma musical e de dança dos escravos de origem Bantu. Os grupos de Jongo preservam esta prática. O Jongo da Serrinha tem sua sede no Morro da Serrinha, no bairro de Madureira, Rio de Janeiro.

${ }^{29}$ Maracatu é outra forma tradicional de música e dança afro-brasileira, tradição de grupos de velhos do estado de Pernambuco.

${ }^{30} \mathrm{http} / / /$ softwarelivre.org/portal/comunidade/pontos-de-cultura-alcancam-84-milhoes-de-pessoas (in nov./16/2010)

${ }^{31}$ http://www.mc.gov.br/noticias-do-site/22528-programa-gesac-amplia-parceria-com-minc-paraconexao-de-pontos-de-cultura (in nov./16/2010)
} 
recursos de até R\$ 500 mil, para adquirir equipamentos e adequar instalações físicas. O financiamento se dá por meio de parcerias com empresas públicas e privadas e governos locais. Trabalham com a perspectiva de capacitar produtores, gestores, artistas e de difundir produtos ${ }^{32}$. E como vimos, vários destes Pontões de Cultura fornecem treinamento para montagem e operação de rádios comunitárias. Mais de 30 estão ligados a Universidades públicas, federais e estaduais.

O Pontão da ECO, por exemplo, oferece Laboratório de Áudio (Gravação, Mixagem e Produção Sonora e Radiofônica e WebRadio), além de Vídeo, de Web (com uso preferencial de aplicativos livres), de desenvolvimento de projetos culturais, de Interferências Sonoras Urbanas com rádio e webrádio, de Circuit Bending.. ${ }^{33}$.A sua participação na criação da radioportoarea, assim, foi uma das atividades de Interferências Sonoras Urbanas com rádio e webrádio...

Muitos jovens formados nestas iniciativas, Pontos, Pontões ou nas ONG's que citei no inicio, têm atuado em suas comunidades e nas favelas, criando centros de comunicação, rádios livres e blogs, a partir da perspectiva política teórica das rádios livres ou novos pólos políticos como o espectroaberto.org, associado ao movimento internacional openspectrum.info. ${ }^{34}$

Crescente atividade micropolítica, em práticas artístico-culturais - grupos de teatro, dança, música, produtores de vídeo e cinema nas periferias urbanas, etc associadas às novas tecnologias de comunicação, aumentam a expectativa de que as novas gerações, com sua continua vivencia comunicativa também potencializada no uso das redes sociais ${ }^{35}$, cheguem a induzir mudanças qualitativas na macropolítica, no Estado, nos governos, que as ações dos partidos políticos e dos sindicatos não vem favorecendo.

${ }^{32}$ http://www.cultura.gov.br/culturaviva/ponto-de-cultura/pontoe/ (in nov./16/2010)

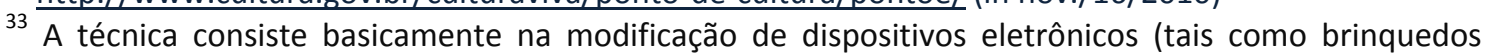
usados ou outros aparelhos) visando à criação de instrumentos musicais com uma sonoridade única, adaptados com uma série de novos recursos (componentes e botões) responsáveis por esta nova sonoridade. V. http://www.ufscar.br/rua/site/?p=1277 (em 09/06/2011)

${ }^{34}$ Ver http://espectroaberto.org/; http://www.radiolivre.org/; http://openspectrum.info/ (in nov./16/2010)

| ${ }^{35}$ A utilização do Facebook, Orkut e Tweeter no Brasil é marcante. Facebook e Orkut são usados principalmente pelos jovens e crianças predominantemente abaixo dos 30 anos. 


\section{Bibliografia:}

DELEUZE, Gilles e GUATTARI, F. Mil Platôs. Capitalismo e Esquizofrenia. Rio de Janeiro: Editora 34, 1995-1997.

MACHADO, Arlindo; MAGRI, Caio; MASAGÃO, Marcelo. Rádios Livres a reforma agrária no ar.São Paulo, Brasiliense, 1986.

COSTA, M. J. S. R. ; HERMANN, Wallace . Rádios livres, rádios comunitárias: outras formas de fazer rádio e política. Lugar Comum (UFRJ), Rio de Janeiro

Claudia de Abreu. Tribuna da Imprensa, Segundo Caderno, Nov./25/1995.

GOMES, Ana Luisa Zaniboni.. "Gritos parados no ar: uma reflexão sobre processos de interdição em rádios comunitárias”. In X Encontro dos Grupos de Pesquisa em Comunicação GP Rádio e Mídia Sonora, INTERCOM, Caxias do Sul, set. 2010.

\section{Sites e blogs consultados:}

http://www.sibila.com.br/index.php/critica/1698-barbaros-e-amerindios-em-mundobraz- (acesso em 20/02/2011)

http://www.unesco.org/pt/brasilia/single-

view/news/unesco_and_the_ngo_jequitiba_promote_a_radio_journalism_training_course_for_c ommunicators_from_community_radio_stations/back/9679/cHash/1a4ba4b513/ (in nov./6/2010)

http://agenciaabraco.org/noticia/72 (in nov./6/2010)

http://pccn.wordpress.com/2010/08/29/ponto-de-cultura-vai-oferecer-oficinas-de-radiocomunitaria-e-radio-web-em-setembro/ (in nov./6/2010)

http://pontodeculturaipiau.blogspot.com/2010/02/oficina-de-radialismo-comunitario-e.html (in nov./6/2010)

http://pontoapontobahia.wordpress.com/remanso-radio-comunitaria-zabele-fm/ (in nov./6/2010)

http://blog.radiocampeche.com.br/2010/05/radio-comunitaria-campeche-98-3-informa/ (in nov./6/2010)

http://www.jornaldelondrina.com.br/online/conteudo.phtml?tl=1\&id=982919\&tit=Politicosaceleram-concessao-de-radios-comunitarias - (in nov./6/2010)

http://www.jurisciencia.com/artigos/coronelismo-eletronico-de-novo-tipo/70/ (in nov./6/2010). http://www.observatoriodaimprensa.com.br/artigos.asp?cod=446IPB006 (in nov./16/2010) 
http://www.mc.gov.br/images/radio-comunitaria/licenciamento/Rel radcom_licenca definitivabrasil 2011-06-13.pdf (acessado em 13 de junho de 2011)

http://www.radiolivre.org/node/884 (in nov./13/2010)

http://www.piratininga.org.br/artigos/2005/64/nogueira-campinas.html (in nov./13/2010)

http://www.portalotamboril.com.br/noticias/-953.html (in nov./13/2010)

http://www.radiolivre.org/node/997 (in nov./13/2010)

http://softwarelivre.org/portal/comunidade/pontos-de-cultura-alcancam-84-milhoes-de-pessoas (in nov./16/2010)

http://www.mc.gov.br/noticias-do-site/22528-programa-gesac-amplia-parceria-com-minc-paraconexao-de-pontos-de-cultura (in nov./16/2010)

http://www.cultura.gov.br/culturaviva/ponto-de-cultura/pontoe/ (in nov./16/2010)

http://www.ufscar.br/rua/site/?p=1277 (em 09/06/2011)

http://espectroaberto.org/ ; http://www.radiolivre.org/ ; http://openspectrum.info/ (in nov./16/2010) 